\title{
Corrosion protection of copper using polypyrrole electrosynthesised from a salicylate solution
}

\author{
V. Annibaldi*, A.D. Rooney, C.B. Breslin \\ Department of Chemistry, National University of Ireland Maynooth, Maynooth, Co. Kildare, Ireland
}

\section{A R T I C L E I N F O}

\section{Article history:}

Received 6 December 2011

Accepted 1 March 2012

Available online 13 March 2012

\section{Keywords:}

A. Copper

C. Polymer coatings

C. Electrodeposited films

B. Cyclic voltammetry

B. Polarisation

\begin{abstract}
A B S T R A C T
Reproducible electrodeposition of adherent and homogeneous polypyrrole was achieved on copper from a salicylate solution. The process was facilitated by the formation of a passive layer which inhibited further dissolution of copper but was sufficiently conducting to allow electropolymerisation. The deposited polymer adopted the characteristic cauliflower morphology. The corrosion protection properties of the coating were assessed using polarisation plots, Tafel analysis, OCP measurements and electrochemical impedance spectroscopy in 0.1 and $0.6 \mathrm{M}(3.5 \% \mathrm{w} / \mathrm{v}) \mathrm{NaCl}$ solutions. The polymer coating was effective in protecting copper and was stable for periods exceeding 2 weeks of immersion in $0.6 \mathrm{M} \mathrm{NaCl}$.
\end{abstract}

๑) 2012 Elsevier Ltd. All rights reserved.

\section{Introduction}

Copper is used extensively in a variety of electrical and electronic devices because of its high electrical and thermal conductivity and mechanical workability [1]. Although copper is more noble than other metals, such as iron, it readily corrodes in certain environments. As a consequence, for reliable applications, it is necessary to improve the corrosion resistance of this metal. Different strategies can be used to achieve protection of copper from corrosion. There is an extensive literature on the use of organic molecules as corrosion inhibitors [2-4]. In particular, azole, benzotriazole and their derivatives are the most investigated molecules as corrosion inhibitors [5,6]. Sol-gel coatings have been used as an alternative approach to provide a barrier layer against corrosion and protect the copper substrate. However, these coatings are degraded at high temperatures [7].

A valid alternative to the use of organic compounds, which can be toxic [8-10], is to utilise conducting polymers. A number of studies have shown that conducting polymers, such as polyaniline and polypyrrole, are promising candidates for the corrosion protection of oxidisable metals [11-19]. Conducting polymers (CPs) are redox-active materials with equilibrium potentials more electropositive than those of the substrate, hence as with chromate, potentially beneficial interactions may occur between CPs and the metal substrate, with a consequent alteration of the corrosion behaviour [18]. The mechanism of corrosion protection depends on the system. In many cases corrosion control is attributed to the

\footnotetext{
* Corresponding author. Tel.: +353 1708 3770; fax: +3531 7083815

E-mail address: valeria.annibaldi@nuim.ie (V. Annibaldi).
}

ability of the polymer to maintain the metal in a passive state [18]. In addition, the polymer acts as a physical barrier and in some cases the rate of the cathodic reaction, such as oxygen reduction, can be minimised [18]. Among the CPs, polyaniline and polypyrrole are the most extensively studied. Polyaniline is less attractive due to the possible presence of benzidine moieties in the polyaniline backbone, which may yield carcinogenic products upon degradation [20]. On the other hand, polypyrrole is biocompatible and unlike polyaniline it does not lead to carcinogenic products of degradation.

Among the coating technologies, electrochemical deposition can be employed to deposit the polymer at irregular shaped objects and the film thickness can be readily controlled by the charge consumed, hence there is significant interest in developing electropolymerisation procedures that generate homogeneous and adherent CPs [21]. In addition, the electrochemical polymerisation is a simple and inexpensive route to deposit conducting polymers on metallic surfaces [22].

Although it is very easy to electropolymerise pyrrole on inert substrates, such as gold or platinum, there are major limitations in the case of oxidisable metal substrates. Thermodynamic data predict that the metal will dissolve before the oxidation potential of the monomer is reached. This leads to poorly adherent and partially degraded polymer films. One of the approaches studied to overcome these limitations is to use anions that will complex with the dissolving copper and passivate the electrode, facilitating the electropolymerisation of the monomer. For example, Herrasti et al. [23] and Tuken et al. [13], have electrodeposited adherent polymers on copper from oxalate solutions, after passivating the electrode in the same monomer containing electrolyte solution. 
Other anions suitable for the electrodeposition of polypyrrole on copper include citrate, acetate and benzoate [24], phosphate [25], saccharinate [14] and salicylate [26].

In the present work, pyrrole was electropolymerised on copper from a salicylate solution. The main advantage of using salicylate as a dopant is that electropolymerisation onto the copper substrate can be attained with relative ease. Passivation of the electrode and oxidation of the monomer can be achieved during the same cycle, as already observed by Lacaze and co-workers [27]. They used cyclic voltammetry, AFM, XPS and FT-IR to characterise these polymers [26,28-31] but did not report on the corrosion protection ability of the films. Since the coating materials obtained from this new process showed promising results that could lead to industrial applications in the corrosion protection of oxidisable substrates [27], we further investigated the properties of these polymer coatings. In this paper results on the corrosion protective properties and long-term stability of salicylate-doped polypyrrole coatings electrodeposited on copper are presented and discussed. The corrosion protection properties of these layers were assessed using electrochemical techniques, in mild and aggressive chloride containing aqueous solutions.

\section{Material and methods}

Pyrrole (98\%) (py), sodium salicylate (99\%) and sodium chloride $(\geqslant 99 \%)$ were purchased from Aldrich. The pyrrole was distilled under vacuum and stored in the dark at $-20^{\circ} \mathrm{C}$. Water was distilled and Milli-Q purified. Copper $(d=3.2 \mathrm{~mm}$, purity $>99.99 \%$ ) was purchased from Goodfellow. The electrodes were prepared from pure copper and embedded in epoxy resin in a Teflon holder. The electrical contact was achieved by means of a wire threaded into the base of the metal sample. The exposed surfaces were first abraded with 1200 grit SiC paper and then polished to a mirror-like finish with Buehler MetaDi monocrystalline diamond suspensions, 30, 15, 6 and $1 \mu \mathrm{m}$, on Buehler microcloths. The electrodes were then rinsed with water and sonicated in acetone for $3 \mathrm{~min}$, rinsed with water and dried under a stream of nitrogen. The electrodes were used for the experiments immediately after the polishing procedure to minimise the air exposure of the copper surface.

Electrochemical experiments were performed using a standard three-electrode cell configuration. A saturated calomel electrode (SCE) was used as the reference electrode and a Pt wire was used as the auxiliary electrode. All potentials quoted in this work are on the SCE scale.

The method employed to electrodeposit the polypyrrole film coatings was adapted from the procedure reported by Lacaze and co-workers [30]. A fresh solution of $0.5 \mathrm{M}$ salicylate was made up in dark glassware. The working solution was freshly prepared prior to each electrodeposition experiment by adding an aliquot of fresh pyrrole to the $0.5 \mathrm{M}$ salicylate solution to obtain a concentration of $0.2 \mathrm{M}$ py. A copper electrode was immersed in the working solution and the polypyrrole coating was electrodeposited by cyclic voltammetry. The applied potential was scanned from 0.00 to $0.60 \mathrm{~V}$ vs SCE, for 20 cycles at a scan rate of $10 \mathrm{mV} / \mathrm{s}$. At the end of the deposition process the electrode was removed from the working solution, rinsed abundantly with water and dried under a gentle stream of nitrogen. Then it was transferred into $0.1 \mathrm{M}$ or $0.6 \mathrm{M} \mathrm{NaCl}$ solution to perform the corrosion tests. For every corrosion test reported in this paper a newly electrosynthesised polymer was used.

Polarisation tests were recorded in chloride-containing solutions from $0.25 \mathrm{~V}$ below the OCP to $0.80 \mathrm{~V}$ vs SCE at a scan rate of $1 \mathrm{mV} / \mathrm{s}$. Tafel plots were also recorded in chloride solutions, using a scan rate of $0.166 \mathrm{mV} / \mathrm{s}$.
A Solartron 1285 potentiostat was used for the electrochemical measurements and coupled with a frequency response analyser, SI 1250, for electrochemical impedance spectroscopy (EIS). Impedance spectra were collected at the open-circuit potential (OCP) using a sinusoidal perturbation amplitude of $10 \mathrm{mV}$.

The microscopy characterisation was performed with a scanning electron microscope (SEM) Hitachi S-3200N, with a tungsten filament electron source. The sample was sputter-coated with an ultrathin gold film using an AGAR automatic sputter coater equipped with an AGAR terminating film thickness monitor unit.

\section{Results and discussion}

\subsection{Formation of the polypyrrole salicylate coating}

The electrosynthesis of the polymer was performed by cyclic voltammetry at a relatively low scan rate, $10 \mathrm{mV} / \mathrm{s}$, since it has been demonstrated that this process yields more adherent and homogeneous deposits [23]. The potential window and the concentration of salicylate were chosen to avoid oxidation of the salicylate. In all cases, the copper electrode was cycled from 0.00 to $0.65 \mathrm{~V}$ vs SCE in $0.5 \mathrm{M}$ salicylate with $0.2 \mathrm{M}$ pyrrole to generate the ppy-sal film.

In Fig. 1 cyclic voltammograms are shown as a function of the cycle number. In the first cycle, a broad peak centred around $0.16 \mathrm{~V}$ vs SCE is observed. This corresponds to dissolution of copper, as discussed by Lacaze and co-workers who fully characterised this process $[26,30]$. Dissolution of copper during this first cycle leads to the deposition of a copper-salicylate layer which hinders further copper dissolution but allows easy deposition of the polypyrrole [26]. The significant increase in the current observed at higher applied potentials, from about 0.50 to $0.65 \mathrm{~V}$ vs SCE, corresponds to the oxidation of the pyrrole monomer. Interestingly, the current reached at $0.65 \mathrm{~V}$ vs SCE decreases after the first cycle and continues to decrease until cycle 5 is reached, at which point a gradual increase in the current is observed. After cycle 5 , the current increases slowly with each subsequent cycle. This trend was observed in all experiments, although the cycle at which the current started to increase varied somewhat from cycle 5 to 8 .

This behaviour can be related to the copper/salicylate deposits, which are formed at the copper surface. Salicylate anions adsorb onto the electrode surface and chelate the copper cations generated from the dissolution of copper [11,32]. This has been confirmed by an in situ atomic force microscopy study [29]. This complex copper/salicylate layer is deposited on a preformed layer

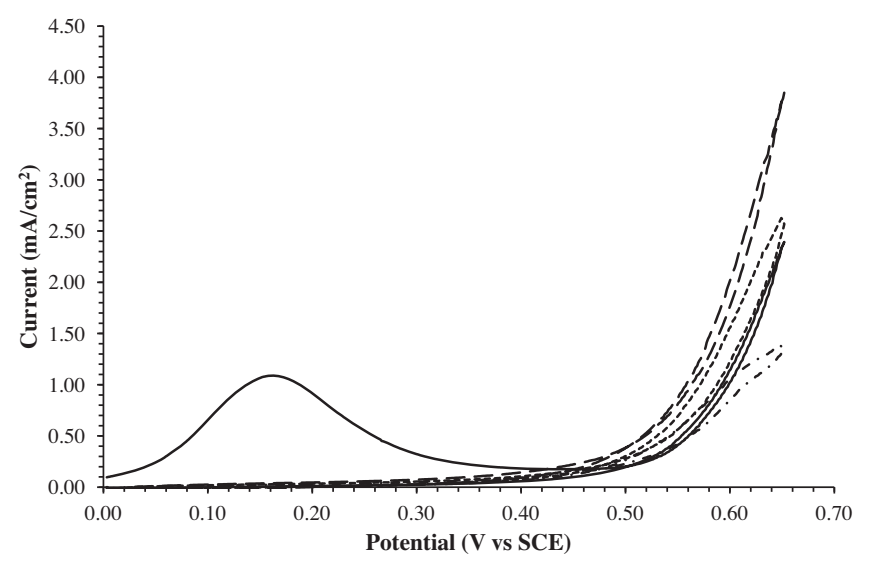

Fig. 1. Electropolymerisation of ppy-sal (from $0.2 \mathrm{M}$ py and $0.5 \mathrm{M}$ salicylate, scan rate $10 \mathrm{mV} / \mathrm{s})$ on $\mathrm{Cu}$. Cycles $1(-), 5(-\bullet-), 10(--)$ and $20(---)$. 
of copper oxides. These layers may contribute to a lowering in the conductivity of the electrode surface. However, after a certain amount of ppy-sal is deposited and a critical active surface is formed, the surface becomes more conducting. Further layers of polymer can now grow on the existing layers, giving rise to an increment in the current recorded at $0.65 \mathrm{~V}$ vs SCE. Although this is a complex process, with the deposition of a copper/salicylate layer followed by the electrodeposition of polypyrrole, very good reproducibility was observed. This is shown in Fig. 2, where cycles 1, 2, 10 and 20 of two different experiments are overlayed. The amount of copper dissolved during the first cycle is similar for the two experiments and the remaining cycles also show very good reproducibility.

In order to prove that the current recorded during the electrosynthesis of the polymer is predominantly due to oxidation and electropolymerisation of the monomer and not to further dissolution of copper, electrodeposition of the polypyrrole salicylate (ppysal) on copper was compared to electrosynthesis of the ppy-sal film at gold. Cyclic voltammograms were recorded in $0.5 \mathrm{M}$ salicylate and $0.2 \mathrm{M}$ pyrrole between 0.00 and $0.65 \mathrm{~V}$ vs SCE at gold and compared to the voltammograms recorded at copper. The currents, observed at 0.55 and $0.65 \mathrm{~V}$ vs SCE, were plotted as a function of the cycle number to give linear plots. The gradients of these plots were computed as $12.5 \pm 1.9$ and $95.4 \pm 11.3 \mu \mathrm{A} / \mathrm{cm}^{2}$ at $0.55 \mathrm{~V}$ vs SCE and $0.65 \mathrm{~V}$ vs SCE, respectively, for the gold electrode, and as $18.4 \pm 4.7 \mu \mathrm{A} / \mathrm{cm}^{2}$ at $0.55 \mathrm{~V}$ vs SCE and $112.0 \pm 19.5 \mu \mathrm{A} / \mathrm{cm}^{2}$ at $0.65 \mathrm{~V}$ vs SCE for the copper electrode $(n=6)$. These slopes show that a similar increment in the current with cycle number is observed with the two different substrates, confirming that most of the current arises from the electropolymerisation of the monomer and is not generated from dissolution of $\mathrm{Cu}$. Furthermore, a simple sellotape test performed on the polymer film deposited at the copper electrode gave $100 \%$ adherence. This is consistent with a stable interface between the copper and the polymer and is a good indication that copper does not dissolve during electropolymerisation.

The SEM micrograph of the polymer depicted in Fig. 3 shows the characteristic cauliflower morphology typical of polypyrrole electrosynthesised on metal substrates [33-35]. There is no evidence of any copper corrosion products on the surface and the polymer is homogenous.

The thickness of this polymer coating was estimated at $1.181 \pm 0.058 \mu \mathrm{m}(n=3)$ using the equation reported by Shinde et al. [11], Eq. 1.

$d=\frac{Q M}{2.303 F \rho}$

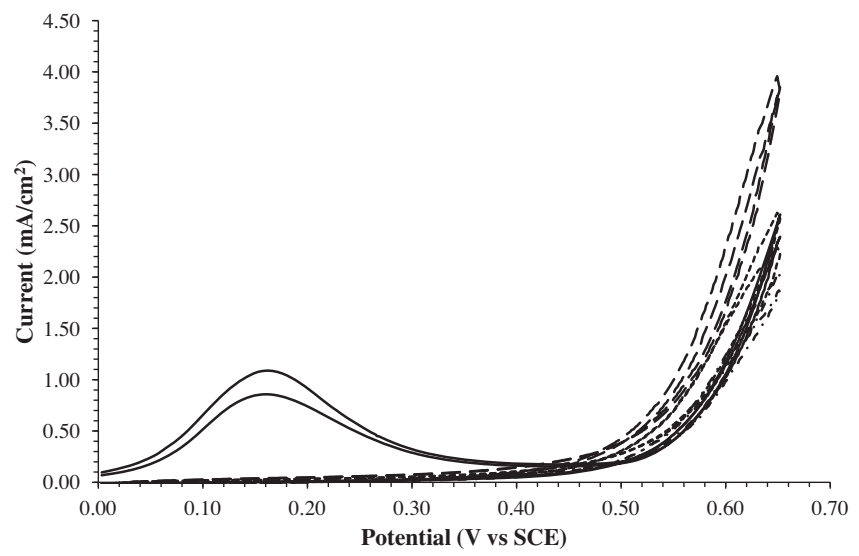

Fig. 2. Reproducibility of the electropolymerisation of ppy-sal (from $0.2 \mathrm{M}$ py and $0.5 \mathrm{M}$ salicylate, scan rate $10 \mathrm{mV} / \mathrm{s})$ on $\mathrm{Cu}$. Cycles $1(-), 2(-\bullet-), 10(---)$ and 20 $(---)$ of two different experiments.

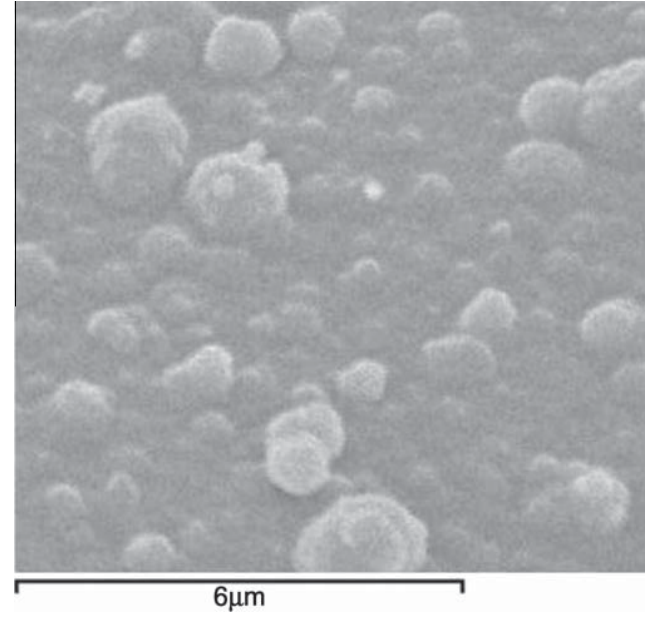

Fig. 3. SEM micrograph of ppy-sal deposited on $\mathrm{Cu}$.

Here, $Q$ is the overall polymerisation charge, $M$ is the molar mass of pyrrole, $\rho$ is the density of polypyrrole $\left(1.48 \mathrm{~g} / \mathrm{cm}^{3}[36]\right)$ and $F$ is Faraday's constant. Shinde and co-workers used Eq. 1 to evaluate the coating thickness of poly(o-ethylaniline) electrosynthesised on a copper substrate and found good agreement with the thickness measured using a conventional magnetic induction based microprocessor controlled coating thickness gauge. However, it must be noted that the film thickness computed is only an approximate measure of the polymer thickness.

\subsection{Corrosion protection performance of the polypyrrole salicylate coating}

The corrosion protection performance of the ppy-sal coatings synthesised on copper was examined in mild and aggressive $\mathrm{NaCl}$ aqueous solutions using potentiodynamic polarisation, open-circuit potential and electrochemical impedance spectroscopy measurements.

Polarisation plots were recorded for the bare copper and ppy-sal coated copper in both $0.1 \mathrm{M} \mathrm{NaCl}$ and $0.6 \mathrm{M} \mathrm{NaCl}(3.5 \% \mathrm{w} / \mathrm{v})$ solutions. Representative polarisation plots are shown in Figs. 4 and 5 recorded in the $0.1 \mathrm{M}$ and $0.6 \mathrm{M} \mathrm{NaCl}$ solutions, respectively. In the $0.1 \mathrm{M} \mathrm{NaCl}$ solution, the plot depicted for uncoated copper is consistent with dissolution of the metal, with a corrosion potential of $-209 \mathrm{mV}$ vs SCE and anodic currents exceeding $1.0 \mathrm{~mA} / \mathrm{cm}^{2}$ at

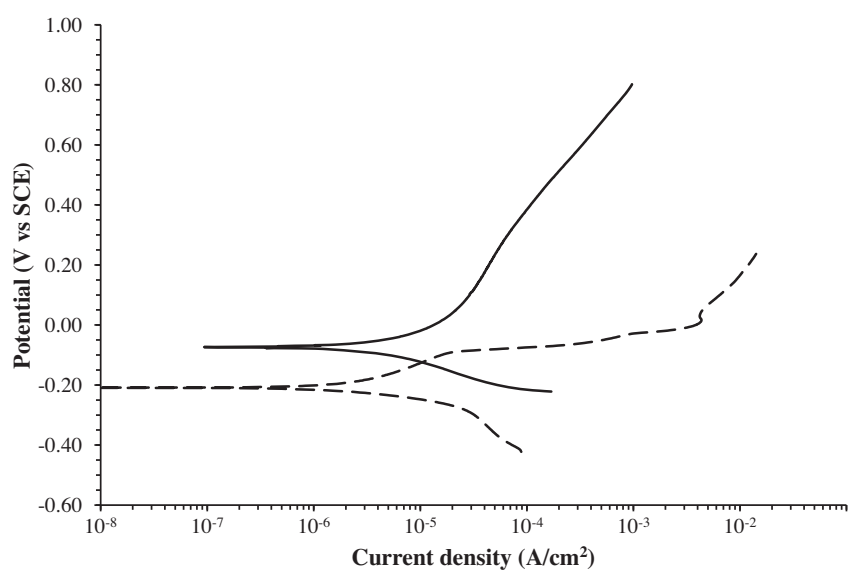

Fig. 4. Potentiodynamic polarisation curves of $\mathrm{Cu}(--)$ and $\mathrm{Cu}$ coated with ppy-sal $(-)$ in $0.1 \mathrm{M} \mathrm{NaCl}$, scan rate $1 \mathrm{mV} / \mathrm{s}$. 


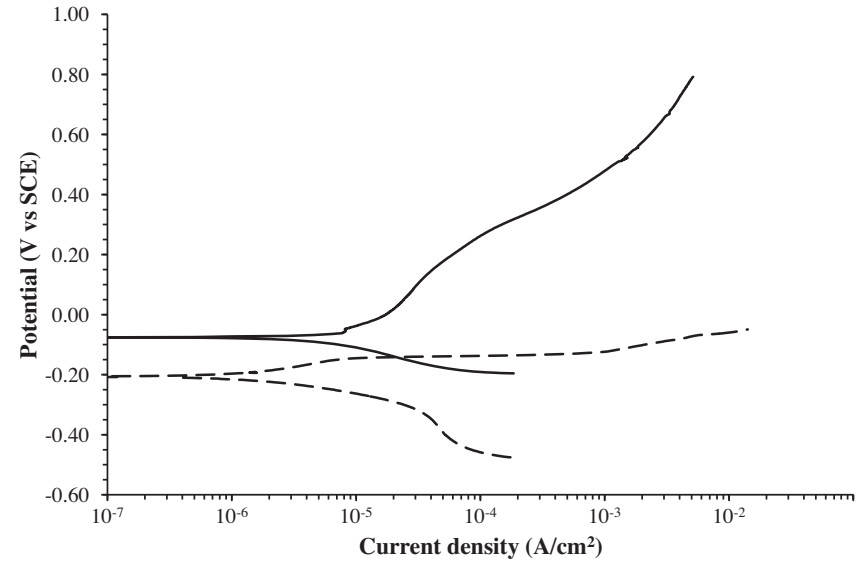

Fig. 5. Potentiodynamic polarisation curves of $\mathrm{Cu}(--)$ and $\mathrm{Cu}$ coated with ppy-sal $(-)$ in $0.6 \mathrm{M} \mathrm{NaCl}$, scan rate $1 \mathrm{mV} / \mathrm{s}$.

potentials higher than $-28 \mathrm{mV}$ vs SCE. The behaviour of the ppysal coated electrode is significantly different. The corrosion potential is $-74 \mathrm{mV}$ vs SCE, $135 \mathrm{mV}$ more positive than that recorded for the bare copper. Furthermore the polymer remains protective at much higher applied potentials with a current of about $0.1 \mathrm{~mA} /$ $\mathrm{cm}^{2}$ measured only at $400 \mathrm{mV}$ vs SCE. As shown in Fig. 5, the polymer coating offers very good corrosion protection in the more concentrated and aggressive $0.6 \mathrm{M} \mathrm{NaCl}$ solution. In this case, a corrosion potential of $-207 \mathrm{mV}$ vs SCE is evaluated for the uncoated copper, while the corrosion potential measured for the polymer-modified electrode is $-76 \mathrm{mV}$ vs SCE.

The estimation of the corrosion current density for copper coated with conducting ppy-sal by linear polarisation is difficult as the current cannot be related to dissolution of the metal substrate. Some of the measured current arises from the redox activity of the polymer. Indeed, when a thicker polymer was deposited on copper, a higher current $\left(I_{\text {mix }}\right)$ was measured, as depicted in Table 1 , clearly highlighting the contribution from the redox activity of the ppy-sal. The corrosion potential evaluated for a thicker polymer is almost identical to the value obtained for the thinner polymer. It seems that the thickness of the polymer does not affect significantly the corrosion protection of ppy-sal. This has been previously observed for related polymers. For example, in a recent study on the corrosion protection of poly(o-ethylaniline) synthesised on copper, the authors presented results on the negligible influence of the polymer thickness on the corrosion protection performance [11]. This suggests that the corrosion protection properties of the system are determined by the polymer formed at the beginning of the deposition process, which is dense and compact and less porous than the subsequent deposited polymer [12].

The interference of the ppy electrochemistry with the estimation of the corrosion current has been discussed in various publications $[12,14]$. In an attempt to reduce the contribution from the polymer a Tafel analysis was performed at a scan rate of $0.166 \mathrm{mV} / \mathrm{s}$ for copper and ppy-sal coated copper, as depicted in Fig. 6. The linear regions were used to compute the parameters listed in Table 2. The values obtained for the corrosion potential are in excellent agreement with polarisation analysis performed

Table 1

Potentiodynamic polarisation results, scan rate $1 \mathrm{mV} / \mathrm{s}$.

\begin{tabular}{llc}
\hline Sample thickness (cycle number) & $E_{\text {corr }}(\mathrm{mV}$ vs SCE $)$ & $I_{\operatorname{mix}}\left(\mu \mathrm{A} / \mathrm{cm}^{2}\right)$ \\
\hline Thin $(20$ cycles $)$ & -76 & 5.17 \\
Thick $(60$ cycles) & -87 & 10.80 \\
\hline
\end{tabular}

at the higher scan rate of $1 \mathrm{mV} / \mathrm{s}$. The calculated corrosion currents were used to estimate the corrosion inhibition efficiency, $\eta$ of the ppy-sal, according to Eq. 2 [25]:

$\eta=\frac{\left(I_{\text {corr }}^{0}-I_{\text {corr }}\right)}{I_{\text {corr }}^{0}} \times 100$

Here, $I_{\text {corr }}^{0}$ and $I_{\text {corr }}$ are the corrosion currents for the uncoated and coated copper, respectively. However a relatively low inhibition efficiency of $52 \%$ is calculated from the experimental data, indicating that the analysis, even at very slow scan rates, is complicated by the redox activity of the polymer. Indeed, the electroactivity of the ppy-sal film is clearly shown in Fig. 7, where ppy-sal was deposited at gold and the polymer-modified gold polarised in $0.6 \mathrm{M} \mathrm{NaCl}$ solution, at a scan rate of $0.166 \mathrm{mV} / \mathrm{s}$. A comparison of the polymermodified gold and bare gold electrodes clearly shows the electroactivity of the polymer. In particular, the currents recorded in the vicinity of the corrosion potential are 10-fold higher for the ppysal coated gold $\left(1.37 \mu \mathrm{A} / \mathrm{cm}^{2}\right)$ compared to $0.13 \mu \mathrm{A} / \mathrm{cm}^{2}$ for the bare gold electrode.

The open-circuit potentials (OCP) recorded for bare and the ppy-sal coated copper plotted as a function of the immersion time in $0.1 \mathrm{M}$ and $0.6 \mathrm{M} \mathrm{NaCl}$ solutions are shown in Fig. 8. The OCP of the ppy-sal coated copper in $0.1 \mathrm{M} \mathrm{NaCl}$ is considerably higher than that measured for the untreated electrode. The OCP of the coated copper reaches a steady-state value of about $60 \mathrm{mV}$ vs SCE. On the other hand, for the untreated copper the OCP drops over the first few hours to reach a stable value of about $-220 \mathrm{mV}$ vs SCE. The difference in the OCP values for the coated and uncoated copper is consistent with that obtained in the polarisation measurements. The OCP of the ppy-sal coated copper was stable for 5 weeks and during the 6th week of immersion, the potential decayed to values close to that of the bare copper indicating a loss in the protective properties of the film. At the higher concentration of $0.6 \mathrm{M} \mathrm{NaCl}$, the OCP was found to be stable for periods in excess of 2 weeks.

The corrosion behaviour of uncoated copper and ppy-sal coated copper was also investigated by EIS. Fig. 9 shows the Nyquist plot (complex plane) recorded at OCP in aqueous $0.6 \mathrm{M} \mathrm{NaCl}$ for the

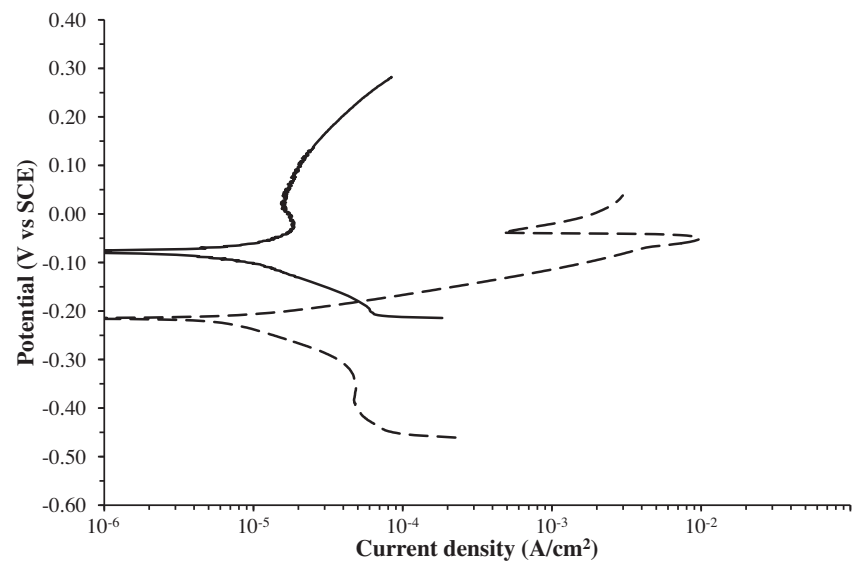

Fig. 6. Tafel curves recorded at $0.166 \mathrm{mV} / \mathrm{s}$, in $0.6 \mathrm{M} \mathrm{NaCl}$ solution for $\mathrm{Cu}(--)$ and Cu coated with ppy-sal (-).

Table 2

Corrosion parameters calculated from Tafel plots for $\mathrm{Cu}$ and ppy-sal coated $\mathrm{Cu}$ in $0.6 \mathrm{M} \mathrm{NaCl}$ solution.

\begin{tabular}{lll}
\hline Sample & $I_{\text {corr }}\left(\mu \mathrm{A} / \mathrm{cm}^{2}\right)$ & $E_{\text {corr }}(\mathrm{mV}$ vs SCE $)$ \\
\hline $\mathrm{Cu}$ & 12.10 & -215 \\
ppy-sal & 5.78 & -76 \\
\hline
\end{tabular}




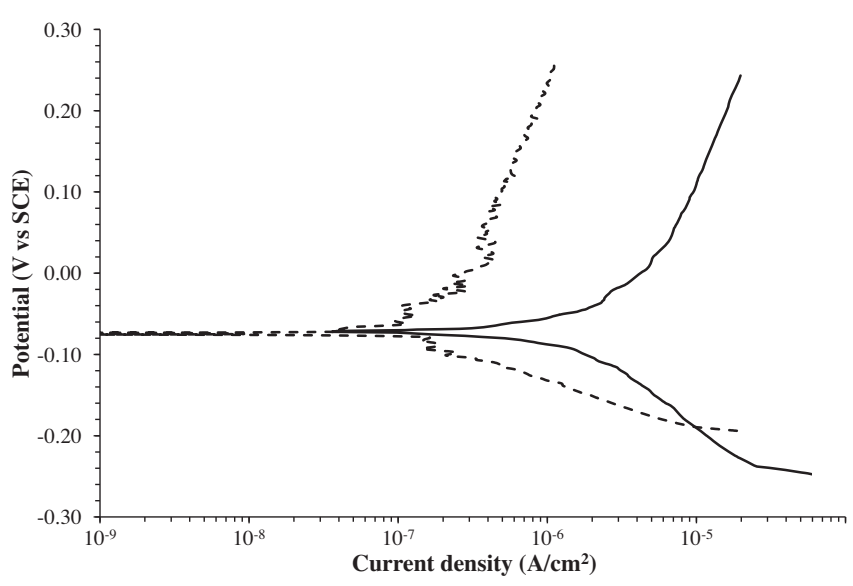

Fig. 7. Tafel curves recorded at $0.166 \mathrm{mV} / \mathrm{s}$, in $0.6 \mathrm{M} \mathrm{NaCl}$ solution for $\mathrm{Au}(\ldots)$ and Au coated with ppy-sal (-).
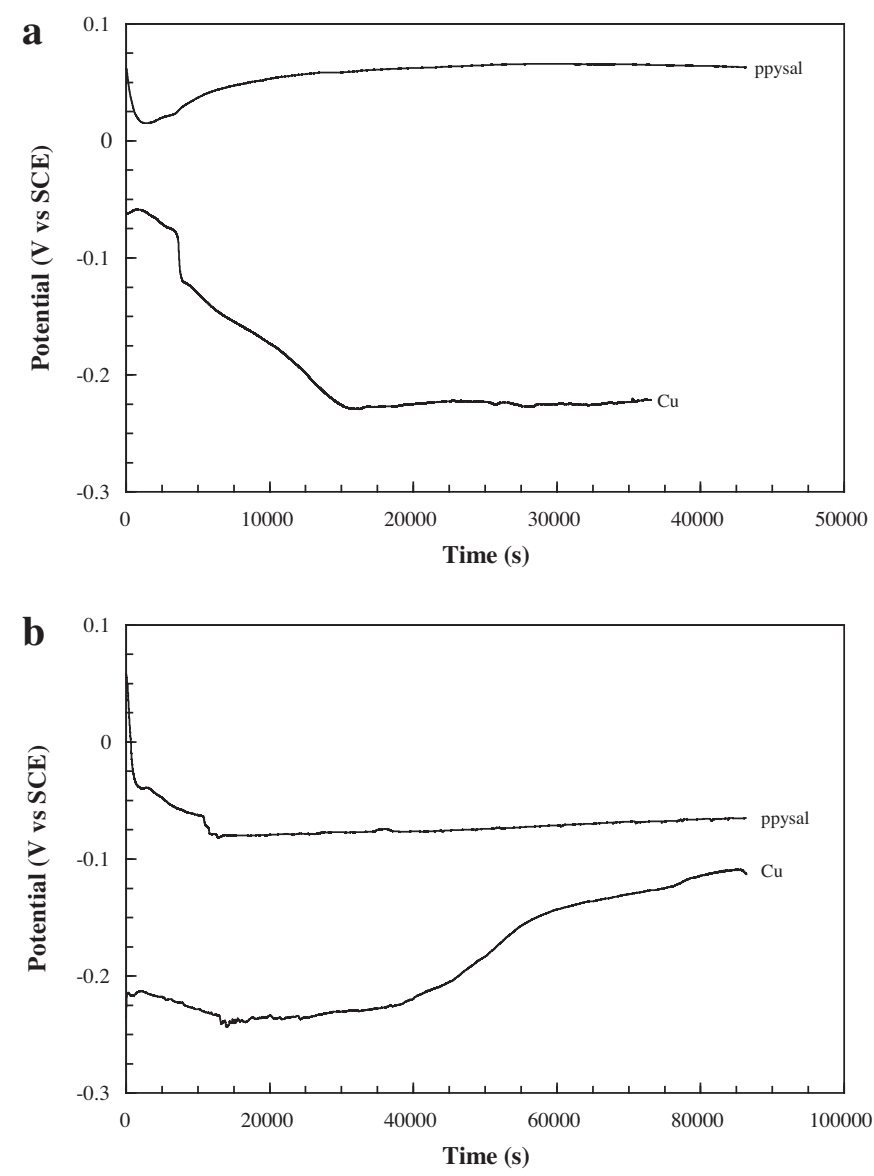

Fig. 8. OCP for uncoated $\mathrm{Cu}$ and for ppy-sal coated $\mathrm{Cu}$ in $0.1 \mathrm{M} \mathrm{NaCl}$ (a) and $0.6 \mathrm{M}$ $\mathrm{NaCl}$ solution (b).

bare copper and for the polymer-coated electrode, after 1, 4 and $8 \mathrm{~h}$ immersion. The Nyquist plot shows two merged semicircles at high and low frequency, Fig. 9a. The spectra recorded for the uncoated copper are typical of a corroding surface in aggressive media $[37,38]$. At the end of the experiment a brownish turbidity was seen in the glass cell, due to precipitation of corrosion products. For longer exposure times the radius of the semicircle, corresponding to the film resistance, increases. Again, this is consistent with the behaviour of corroding metals [37-39]. The prolonged dissolution of the metal gives rise to the deposition of a corrosion product
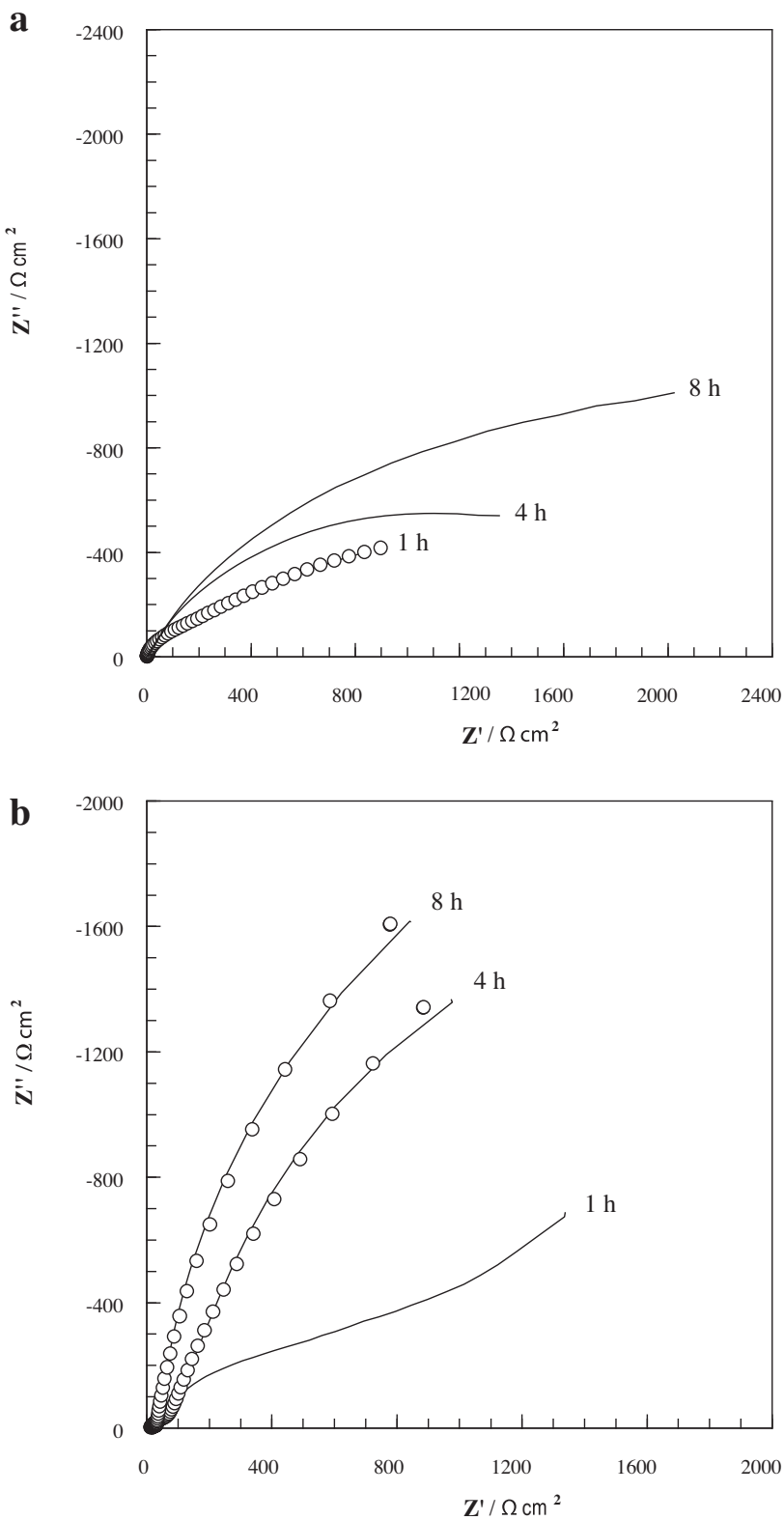

Fig. 9. Nyquist plots for uncoated $\mathrm{Cu}$ (a) and ppy-sal-coated $\mathrm{Cu}$ (b), after 1, 4 and $8 \mathrm{~h}$ immersion in $0.6 \mathrm{M} \mathrm{NaCl}$, - experimental results, $\bigcirc$ fitted results.

layer, comprising copper oxides/hydroxides and various copper chloride species, and as this layer increases in thickness and ages, there is a corresponding increase in the measured film resistance [39].

The impedance data recorded for the ppy-sal coated copper are very different, as shown in Fig. 9b. These data were fit to the equivalent circuit shown in Fig. 10. Good agreement between the simulated and the experimental data was obtained as shown in the figure, where the symbols represent the simulated data and the solid traces correspond to the experimental data. This circuit represents a two-time constant model, where Rs refers to the solution resistance, and R1 and R2 correspond to resistance and CPE1 and CPE2 are constant phase elements. A CPE is commonly employed to compensate for the inhomogeneous characteristics and nonideal capacitive behaviour of conducting polymer modified electrodes $[40,41]$. The impedance of a constant phase element is described by the relationship in Eq. 3 , where $j$ is the imaginary unit and $\omega$ the angular frequency. When the fractional exponent, $n$, 


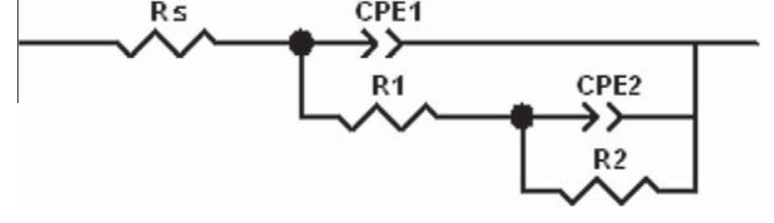

Fig. 10. Equivalent circuit used to model impedance spectra.

approaches 1.0, ( $n \geqslant 0.9)$ the CPE represents an ideal capacitor and $Q$ corresponds to the capacitance.

$Z_{C P E}=\frac{1}{Q(j \omega)^{n}}$

The $n$ values of the CPE1 element were too low, typically 0.76 , to represent a capacitance. However, the CPE1 values remained essentially constant over the $8 \mathrm{~h}$ immersion. R1 refers to the charge transfer resistance at the metal polymer interface. The second loop at low frequency was interpreted with a CPE2, representing the film pseudo-capacitance, and a resistance, R2, representing the film resistance, which includes the polymer resistance, the resistance of the salicylate and oxide layer deposited on the metal surface during the early stage of electropolymerisation and the resistance of the electrolyte contained within the pores of the polymer. In this case, CPE2 was characterised by $n$ values varying between 0.83 and 0.93 , hence the $Q$ values give a reasonable interpretation of the distorted capacitance of the film. Again, $Q$ values computed were relatively constant, varying between 4 and $6 \mathrm{mF} / \mathrm{cm}^{2}$. These high capacitance values are in good agreement with the charge storage ability typically displayed by polypyrrole films $[12,15,42-44]$.

The two semicircles are visible after $3 \mathrm{~h}$ of immersion in the highly concentrated chloride solution, as evident from Fig. 9b. However, during the first $2 \mathrm{~h}$ of immersion the impedance plots are dominated by diffusion processes, indicating that the corrosion process is diffusion controlled with diffusion of the chloride species through the pores of the polymer film.

In Table 3, the parameters computed from fitting of the impedance data of the ppy-sal coated copper recorded from 3 to $8 \mathrm{~h}$ immersion times are summarised together with the OCP values, which remain well above the OCP value for bare copper. Included for comparison is the fitting of the bare copper system, again to the equivalent circuit shown in Fig. 10. In this case, the R2 represents the resistance of the deposited corrosion film. Parameters extrapolated for the bare metal are in agreement with already published literature $[25,45]$. Both resistance values are significantly higher for the ppy-sal coated copper than for the bare copper, highlighting the corrosion protection offered by the polymer. Interestingly, there is a gradual decrease in charge transfer resistance, R1 and a gradual increase in the film resistance $\mathrm{R} 2$ with increasing immersion time. This decrease in $\mathrm{R} 1$ has been observed previously by Tuken [46] and Grgur et al. [44] who investigated the corrosion protection of polypyrrole coatings electrodeposited from oxalic

Table 3

Fitted parameters for impedance spectra of the uncoated and ppy-sal coated $\mathrm{Cu}$ after immersion in $0.6 \mathrm{M} \mathrm{NaCl}$ solution.

\begin{tabular}{llcll}
\hline Sample & Immersion time $(\mathrm{h})$ & $\mathrm{R} 1\left(\Omega \mathrm{cm}^{2}\right)$ & $\mathrm{R} 2\left(\Omega \mathrm{cm}^{2}\right)$ & $\mathrm{OCP}(\mathrm{mV}$ vs SCE $)$ \\
\hline $\mathrm{Cu}$ & 1 & 80 & 2629 & -220 \\
ppy-sal & 3 & 205 & 5797 & -74 \\
ppy-sal & 4 & 89 & 7172 & -70 \\
ppy-sal & 5 & 41 & 7244 & -67 \\
ppy-sal & 6 & 26 & 7308 & -62 \\
ppy-sal & 7 & 20 & 7405 & -56 \\
ppy-sal & 8 & 18 & 7349 & -50 \\
\hline
\end{tabular}

acid solutions and it can be explained by a redox reaction between the copper and the ppy-sal [44], where the ppy-sal is reduced and the copper is oxidised. Accordingly the R1 term approaches the value obtained for the bare copper after $4 \mathrm{~h}$, Table 3 .

On the other hand, the growth of an oxide film under the polymer would increase the second resistance parameter R2 (Table 3), which represents the resistance of the polypyrrole and the passive layer underneath. Indeed an increase of the film resistance was observed over time, as evident in Table 3.

\section{Conclusions}

Reproducible electrodeposition of adherent and homogeneous polypyrrole was successfully achieved on copper from a sodium salicylate solution by means of cyclic voltammetry. The process was facilitated by the formation of a passive layer which inhibited further dissolution of copper but was sufficiently conducting to allow electropolymerisation. The positive potential shift of the corrosion potential observed for the ppy-sal coated copper provided evidence that this polymer exhibited significant corrosion protection both in $0.1 \mathrm{M} \mathrm{NaCl}$ and in a more aggressive $0.6 \mathrm{M}(3.5 \% \mathrm{w} /$ v) $\mathrm{NaCl}$ solution. The corrosion current could not be computed because of the contribution of the ppy-sal electroactivity to the overall current recorded when a Tafel analysis was performed. Comparative experiments performed on a gold electrode highlighted this concept.

The polymer coating was stable for periods exceeding 4 weeks of immersion in $0.1 \mathrm{M} \mathrm{NaCl}$ and for periods exceeding 2 weeks of immersion in the highly aggressive $0.6 \mathrm{M} \mathrm{NaCl}$ solution. EIS measurements suggested that a redox reaction between the metal and the ppy-sal contributed to the corrosion protection process.

\section{Acknowledgement}

The authors are grateful to acknowledge the support of this work by Science Foundation Ireland through the Research Frontiers Programme 08/RFP/MTR1261.

\section{References}

[1] A.H. Jafari, S.M. Hosseini, E. Jamalizadeh, Electrochim. Acta 55 (2010) 90049009.

[2] R. Solmaz, E.A. Sahin, A. Doner, G. Kardas, Corros. Sci. 53 (2011) 3231-3240.

[3] H. Ma, S. Chen, L. Niu, S. Zhao, S. Li, D. Li, J. Appl. Electrochem. 32 (2002) 65-72.

[4] D.Q. Zhang, L.X. Gao, G.D. Zhou, Corros. Sci. 46 (2004) 3031-3040.

[5] N.K. Allam, A.A. Nazeer, E.A. Ashour, J. Appl. Electrochem. 39 (2009) 961-969.

[6] Z. Khiati, A.A. Othman, M. Sanchez-Moreno, M.C. Bernard, S. Joiret, E.M.M. Sutter, V. Vivier, Corros. Sci. 53 (2011) 3092-3099.

[7] D. Wang, G.R. Bierwagen, Progr. Org. Coat. 64 (2009) 327-338.

[8] E. Stupnisek-Lisac, A.L. Bozic, I. Cafuk, Corrosion 54 (1998) 713-720.

[9] G.K. Gomma, Mater. Chem. Phys. 56 (1998) 27-34.

[10] S.A.A. El-Maksoud, Electrochim. Acta 49 (2004) 4205-4212.

[11] V. Shinde, A.B. Gaikwad, P.P. Patil, Surf. Coat. Technol. 202 (2008) 2591-2602.

[12] A.M. Fenelon, C.B. Breslin, Electrochim. Acta 47 (2002) 4467-4476.

[13] T. Tuken, A.B. Cavusoglu, E. Altunbas, M. Erbil, Progr. Org. Coat. 71 (2011) $153-$ 161.

[14] A. Bazzaoui, J.I. Martins, E.A. Bazzaoui, L. Martins, E. Machnikova, Electrochim. Acta 52 (2007) 3568-3581.

[15] E. Machnikova, M. Puderova, M. Bazzaoui, N. Hackerman, Surf. Coat. Technol. 202 (2008) 1543-1550.

[16] B. Zeybek, N.O. Pekmez, E. Kilic, Electrochim. Acta 56 (2011) 9277-9286.

[17] R.L. Twite, G.P. Bierwagen, Progr. Org. Coat. 33 (1998) 91-100.

[18] D.E. Tallman, G. Spinks, A. Dominis, G.G. Wallace, J. Solid State Electrochem. 6 (2002) 73-84.

[19] G.M. Spinks, A.J. Dominis, G.G. Wallace, D.E. Tallman, J. Solid State Electrochem. 6 (2002) 85-100.

[20] J. Wang, Y. Xu, X. Sun, S. Mao, F. Xiao, J. Electrochem. Soc. 154 (2007) C445C450.

[21] C.B. Breslin, A.M. Fenelon, K.G. Conroy, Mater. Design 26 (2005) 233-237.

[22] T.A. Skotheim, R.J. Reynolds, Handbook of Conducting Polymers CRC Press, Taylor and Francis Group, New York, 2007.

[23] P. Herrasti, A.L. del Rio, J. Recio, Electrochim. Acta 52 (2007) 6496-6501. 
[24] M. Sharifirad, A. Omrani, A.A. Rostami, M. Khoshroo, J. Electroanal. Chem. 645 (2010) 149-158.

[25] M.I. Redondo, C.B. Breslin, Corros. Sci. 49 (2007) 1765-1776.

[26] A.C. Cascalheira, S. Aeiyach, P.C. Lacaze, L.M. Abrantes, Electrochim. Acta 48 (2003) 2523-2529.

[27] J. Petitjean, S. Aeiyach, J.C. Lacroix, P.C. Lacaze, J. Electroanal. Chem. 478 (1999) $92-100$.

[28] J. Petitjean, J. Tanguy, J.C. Lacroix, K.I. Chane-Ching, S. Aeiyach, M. Delamar, P.C. Lacaze, J. Electroanal. Chem. 581 (2005) 111-121.

[29] A.C. Cascalheira, A.S. Viana, L.M. Abrantes, Electrochim. Acta 53 (2008) 57835788.

[30] L.M.M. dos Santos, J.C. Lacroix, K.I. Chane-Ching, A. Adenier, L.M. Abrantes, P.C. Lacaze, J. Electroanal. Chem. 587 (2006) 67-78.

[31] A.C. Cascalheira, L.M. Abrantes, Electrochim. Acta 49 (2004) 50235028

[32] A.C. Cascalheira, S. Aeiyach, J. Aubard, P.C. Lacaze, L.M. Abrantes, Russ. J. Electrochem. 40 (2004) 294-298.

[33] W.C. Su, J.O. Iroh, Synth. Met. 95 (1998) 159-167.
[34] M. Bazzaoui, L. Martins, E.A. Bazzaoui, J.I. Martins, Electrochim. Acta 47 (2002) 2953-2962.

[35] A.S. Liu, M.A.S. Oliveira, J. Braz. Chem. Soc. 18 (2007) 143-152.

[36] Z.G. Qi, P.G. Pickup, Chem. Mater. 9 (1997) 2934-2939.

[37] H.E. El-Feky, N.H. Helal, M.R. Negem, Mater. Corros. 61 (2010) 599-610.

[38] S. Yuan, S.O. Pehkonen, B. Liang, Y.P. Ting, K.G. Neoh, E.T. Kang, Corros. Sci. 53 (2011) 2738-2747.

[39] X. Liao, F. Cao, L. Zheng, W. Liu, A. Chen, J. Zhang, C. Cao, Corros. Sci. 53 (2011) 3289-3298.

[40] X.M. Ren, P.G. Pickup, J. Electrochem. Soc. 139 (1992) 2097-2105

[41] J.F. Rubinson, Y.P. Kayinamura, Chem. Soc. Rev. 38 (2009) 3339-3347.

[42] E. Andreoli, V. Annibaldi, D.A. Rooney, K.-S. Liao, N.J. Alley, S.A. Curran, C.B. Breslin, Electroanalysis 23 (2011) 2164-2173.

[43] X.M. Ren, P.G. Pickup, Electrochim. Acta 41 (1996) 1877-1882.

[44] B.N. Grgur, N.V. Krstajic, M.V. Vojnovic, C. Lacnjevac, L. Gajic-Krstajic, Progr. Org. Coat. 33 (1998) 1-6.

[45] K.M. Yin, H.Z. Wu, Surf. Coat. Technol. 106 (1998) 167-173.

[46] T. Tuken, Surf. Coat. Technol. 200 (2006) 4713-4719. 